\title{
Case Report: The Subcutaneous Injection of Organophosphate: A Case Report
}

\author{
Shafeajafar Zoofaghari' ${ }^{1}$ (D, Afshar Fazeli Dehkordi ${ }^{1}$, Kourosh Nemati ${ }^{1}$, Mozhdeh Hashemzadeh ${ }^{2 *}$ (D), Arman Otroshi
}

1. Isfahan Clinical Toxicology Research Center, Department of Clinical Toxicology, Isfahan University of Medical Sciences, Isfahan, Iran. 2. Department of Medical Library and Information Science, School of Management and Medical Informat, Sciences, Clinical Informationist Research Group, Isfahan University of Medical Sciences, Isfahan, Iran.

\begin{tabular}{|c|c|}
\hline $\begin{array}{l}\text { Use your device t scan } \\
\text { and read the article online }\end{array}$ & Citation Zoofaghari S, Fazeli Dehkordi A, Nemati K, Hashemzadeh M, Otroshi A. The Subcutaneous Injection of Organo- \\
\hline 口iritip & $\begin{array}{l}\text { phosphate: A Case Report. International Journal of Medical Toxicology and Forensic Medicine. 2021; 11(4):34343. https://doi. } \\
\text { org/10.32598/ijmtfm.v11i4.34343 }\end{array}$ \\
\hline 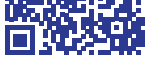 & del https://doi.org/10.32598/ijmtfm.v11i4.34343 \\
\hline
\end{tabular}

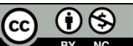

Article info:

Received: 10 Mar 2021

First Revision: 16 Mar 2021

Accepted: 02 Jun 2021

Published: 21 Dec 2021

\section{Keywords:}

Organophosphate poisoning,

Diazinon, Injections,

Subcutaneous, Case report

\section{ABSTRACT}

Organophosphate (OP) poisoning is prevalent in developing countries. Toxicity occurs by voluntary injection, inhalation, and absorption. Self-injection is rare. The current case report describes a 61-y/o male with subcutaneous self-injected one cc OP poisoning presenting with delayed drowsiness, nausea, and vomiting. He was treated and presented a good clinical response to treatment with pralidoxime and had a successful recovery. Diagnosis of OP compound toxicity by the parenteral route is a challenge. By observing patients, the dose, and the time between poisoning until the time to start treatment, we can conclude different presentations and outcomes of OP poisoning.

\section{Introduction}

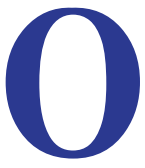

rganophosphate (OP) refers to various chemicals, i.e., found in some products worldwide. OPs are used in agricultural productivity and control deadly vectorborne illnesses [1]. OPs poisoning is common in developing countries [2]. Poisoning occurs mainly by voluntary ingestion, inhalation, or absorption through the skin [3]. Toxicity can also rarely occur by self-injection through an intramuscular or intravenous route [4]. Some cases manifested local and another systemic toxicity symptom [5]. We describe a case of selfinjected one cc Organophosphate (Diazinon) poisoning around the umbilicus. Interestingly, the onset of the patient's clinical symptoms began with a delay of about 8 hours and the kind of poison (Diazinon). The literature review in the PubMed database reported 172 cases in which the OP was used for suicide.

* Corresponding Author:

Mozhdeh Hashemzadeh, PhD. candidate.

Address: Department of Medical Library and Information Science, School of Management and Medical Informat, Sciences, Clinical Informationist Research Group, Isfahan University of medical sciences, Isfahan, Iran.

Tel: +98 (913) 4066356

E-mail: mojdeh.hashemzadeh@gmail.com 


\section{Case Presentation}

A $61 \mathrm{y} / \mathrm{o}$ male was admitted to the hospital by EMS. He presented drowsiness, weakness, vomiting, and diarrhea 8 hours after the self-injection of $1 \mathrm{cc}$ of OP (Diazinon) around the umbilicus subcutaneously (He had no history of specific diseases). He was transferred to the Intensive Care Unit (ICU) due to cholinergic symptoms such as Sweating, diarrhea, and vomiting. He had a history of having attempted suicide one time with eating OP. Vital signs revealed a pulse rate of $91 /$ minute, blood pressure of $140 / 80 \mathrm{mmHg}$, respiratory rate of 18 per minute, temperature 36.9 , and pulse oximeter showing $96 \%$ saturation on room air (results of laboratory tests in admission show in Table 1). Neurological examination revealed normal cranial nerves. Miosis was detected bilaterally, reacting to light absent Doll's eye movement. Deep tendon reflexes were $2+$. The examination of the chest was regular. No crackles were heard on chest auscultation. The examination of other systems was normal. Blood gas analysis showed typical values. Chest X-ray was clear. EKG, cardiac enzymes, and CBC were normal. The plasma cholinesterase test was 3867(normal range: 4000-12000 IU/L). Later in the first day, he developed abdominal pain and Cramps. He was treated with hyoscine and pralidoxime. Hyoscine was given $10 \mathrm{mg}$ PO $\mathrm{q} 6 \mathrm{~h}$ and pralidoxime infused at the rate of $300 \mathrm{mg} / \mathrm{h}$ after 1.5 gr bolus IV. Response to pralidoxime treatment was reasonable, and pralidoxime infusion was continued for two days. His pain was controlled with hyoscine. He was finally discharged from the hospital on day 4 .

\section{Discussion}

OP's products were used as insecticides worldwide for several years [6]. Global research indicated that 3000000 individuals are exposed to OP annually, with up to 300000 fatalities. Toxicity generally results from the accidental or deliberate ingestion of, or exposure to, agricultural pesticides [7]. Suicidal poisoning is common in developing countries [8-10].

OP might be absorbed by any route, including transdermal, transconjunctival, inhalation, across the GI or genitourinary mucosa, and direct injection [11]. The onset of systemic symptoms may occur in 5 minutes with inhala- tion. Most patients develop symptoms within 12 hours of ingestion, unless exposure to fat-soluble organophosphates has occurred or if significant metabolic activation must occur [12]. Effect's manifestations vary per the plane of administration. With self-injection, symptoms will appear after some delay, and if the quantity administered is less, there may be only a local abscess [2].

The medical management of patients poisoned with OP is complex and protracted. All symptomatic patients should receive therapy with oxygen, atropine, oxime (e.g., pralidoxime), and benzodiazepines (e.g., diazepam) [7].

Initial treatment must focus on the adequate use of atropine. Optimizing oxygenation before using atropine is also recommended to minimize the potential for dysrhythmias [13]. Patients with significant respiratory muscle weakness are usually treated with an oxime. Treatment with oximes may be most effective when started early. Oximes are generally continued as long as atropine is continued [14]. Diazepam is used to treat seizures caused by exposure to OP pesticide after $30 \mathrm{~min}$ post-exposure to the OP chemical or seizure onset [15].

Diazinon is an OP insecticide that causes toxic effects on some organs, such as liver enzymes [16]. In the present case report, the patient was self-injected one cc of diazinon poison into his umbilicus to commit suicide. After 8 hours of injection, he demonstrated symptoms, such as drowsiness, nausea, and vomiting.

Findings from a retrospective study of 220 cases in Romania revealed that diazinon is among the most common organophosphate products in causing poisoning. The onset of symptoms in patients taking diazinon was reported to be between 1 and 14 hours, and the toxin has been used primarily for suicide. These findings are in line with the present case report [17].

Contrary to the present study data, literature review in the PubMed, ISI, and Embase databases reported the onset of symptoms of organophosphate compounds poisoning to range between 30 minutes and 2.5 hours. In the present study, the onset of symptoms was delayed by 8 hours $[18,19]$.

Table 1. Results of laboratory tests at admission

\begin{tabular}{cccccccc}
\hline BUN & Cr & AST & ALT & ALKP & Sodium & Potssium & Magnesium \\
\hline 19 & 1.02 & 27 & 34 & 308 & 137 & 3.3 & 1.7 \\
\hline & & & & & & & $\begin{array}{l}\text { International Journal of } \\
\text { Medical Toxicology \& For Ensic Medicin }\end{array}$
\end{tabular}




\section{Conclusion}

OP compound toxicity by parenteral route is a diagnostic challenge. Under the observation of these patients, concluded different presentations and outcomes of OP poisoning depend not only on the pesticide, the dose, and the time between poisoning and start of treatment but also on the route of poisoning.

\section{Ethical Considerations}

\section{Compliance with ethical guidelines}

A written consent has been obtained from the subjects.

\section{Funding}

This research did not receive any grant from funding agencies in the public, commercial, or non-profit sectors.

\section{Author's contributions}

All authors equally contributed to preparing this article.

\section{Conflict of interest}

The authors declared no conflict of interest.

\section{Acknowledgements}

Research Team Appreciates clinical informationist research center dependent on Deputy of research and technology of Isfahan University of Medical Sciences

\section{References}

[1] Naughton SX, Terry AV Jr. Neurotoxicity in acute and repeated organophosphate exposure. Toxicology. 2018; 408:101-12. [DOI:10.1016/j.tox.2018.08.011] [PMID] [PMCID]

[2] Pandit V, Seshadri S, Rao SN, Samarasinghe C, Kumar A, Valsalan R. A case of organophosphate poisoning presenting with seizure and unavailable history of parenteral suicide attempt. J Emerg Trauma Shock. 2011; 4(1):132-4. [DOI:10.4103/0974-2700.76825] [PMID] [PMCID]

[3] Badhe A, Sudhakar S. An intravenous organophosphate poisoning with intermediate syndrome: An unusual way of intoxication. Indian J Crit Care Med. 2006; 10(3):191-2. [DOI:10.4103/0972-5229.27862]
[4] Lyon J, Taylor H, Ackerman B. A case report of intravenous malathion injection with determination of serum half-life. J Toxicol Clin Toxicol. 1987; 25(3):243-9. [PMID]

[5] Ghosh S. Atypical manifestations of organophosphorus poisoning following subcutaneous injection of Dichlorvos with suicidal intention. Indian J Crit Care Med. 2014; 18(4):244-6. [DOI:10.4103/0972-5229.130578] [PMID] [PMCID]

[6] Güven M, Unlühizarci K, Göktaş Z, Kurtoğlu S. Intravenous organophosphate injection: An unusual way of intoxication. Hum Exp Toxicol. 1997; 16(5):279-80. [DOI:10.1177/0960327 19701600509] [PMID]

[7] Bird S. Organophosphate and carbamate poisoning [Internet]. 2020 [Updated 2021 January 25]. Available from: https://www.uptodate.com/contents/organophosphate-andcarbamate-poisoning

[8] Liu H, Kan B, Jian X, Zhang W, Zhou Q, Wang J. Parasuicidal poisoning by intramuscular injection of insecticide: A case report. Exp Ther Med. 2013; 6(3):696-8. [DOI:10.3892/ etm.2013.1216] [PMID] [PMCID]

[9] Soummer A, Megarbane B, Boroli F, Arbelot C, Saleh M Moesch C, et al. Severe and prolonged neurologic toxicity following subcutaneous chlorpyrifos self-administration: A case report. Clin Toxicol (Phila) 2011; 49(2):124-7. [PMID]

[10] Yucel I, Demiraran Y, Alper M. Suicide attempt with injection of insecticide in both wrists. Orthopedics. 2008; 31(2):174. [DOI:10.3928/01477447-20080201-40] [PMID]

[11] Badrane N, Askour M, Berechid K, Abidi K, Dendane $\mathrm{T}$, Zeggwagh AA. Severe oral and intravenous insecticide mixture poisoning with diabetic ketoacidosis: A case report. BMC Res Notes. 2014; 7:485. [DOI:10.1186/1756-0500-7-485] [PMID] [PMCID]

[12] Bala I, Pratap M, Nakra D, Ramprabhu T. Prolonged cholinergic crisis and compartment syndrome following subcutaneous injection of an organophosphate compound for suicide attempt. J Forensic Leg Med. 2008; 15(4):256-8. [DOI:10.1016/j. jflm.2007.07.008] [PMID]

[13] Medscape. Organophosphate toxicity medication [Internet]. 2020 [Updated 2020 December 31]. Available from: https://emedicine.medscape.com/article/167726-medication

[14] Due P. Effectiveness of high dose pralidoxime for treatment of organophosphate poisoning. Asia Pac J Med Toxicol. 2014; 3(3):97-103. [DOI:10.22038/APJMT.2014.3377]

[15] Kuruba R, Wu X, Reddy DS. Benzodiazepine-refractory status epilepticus, neuroinflammation, and interneuron neurodegeneration after acute organophosphate intoxication. Biochim Biophys Acta Mol Basis Dis. 2018; 1864(9 Pt B):2845-58. [DOI:10.1016/j.bbadis.2018.05.016] [PMID] [PMCID]

[16] Ogutcu A, Uzunhisarcikli M, Kalender S, Durak D, Bayrakdar F, Kalender Y. The effects of organophosphate insecticide diazinon on malondialdehyde levels and myocardial cells in rat heart tissue and protective role of vitamin E. Pestic Biochem Physiol. 2006; 86(2):93-8. [DOI:10.1016/j. pestbp.2006.01.010]

[17] Yurumez Y, Durukan P, Yavuz Y, Ikizceli I, Avsarogullari L, Ozkan S, et al. Acute organophosphate poisoning in university hospital emergency room patients. Intern Med. 2007 46(13):965-9. [DOI:10.2169/internalmedicine.46.6304] [PMID] 
[18] Dhooria S, Behera D, Agarwal R. Amitraz: A mimicker of organophosphate poisoning. BMJ Case Rep. 2015 2015:bcr2015210296. [DOI:10.1136/bcr-2015-210296] [PMID] [PMCID]

[19] Licata C, Liu L, Mole D, Thorp J, Chand R, Chaulagain S. Social and cultural factors leading to suicide attempt via organophosphate poisoning in Nepal. Case Rep Psychiatry. 2019, 2019:7681309. [DOI:10.1155/2019/7681309] [PMID] [PMCID] 